\title{
Electric Vehicle Applications in Agriculture and its Prospects
}

\section{Run Xu*}

Yantai University, WenJing College, Mechanical Electricity Dept. Yantai 264005, China

DOI: $\underline{10.36348 / \text { sjet.2020.v05i11.002 }}$ | Received: 16.10 .2020 | Accepted: 04.11 .2020 | Published: 06.11 .2020

*Corresponding author: Run Xu

\section{Abstract}

The electric vehicle as its precious control will be applied widely in agriculture manufacture and transportation that is thought. They are applicable and have future focus in electric vehicle by now. The main advantage is it precision and rapidness to compare traditional vehicle. The second is clear and safe to our environment that will protect energy over use. The third is that cost decreasing due to their unified specification. It allows us to produce rapidly and largely in every area.

Keywords: Electric Vehicle; Applications; Agriculture; precision and rapidness; environment; cost decreasing; unified specification.

Copyright (C) 2020 The Author(s): This is an open-access article distributed under the terms of the Creative Commons Attribution 4.0 International License (CC BY-NC 4.0) which permits unrestricted use, distribution, and reproduction in any medium for non-commercial use provided the original author and source are credited.

\section{INTRODUCTION}

The electric vehicle is gradually popular in modern life as a safe and non-contamination tool. The hybrid power vehicle is a main future product that is designed and planed by many investment capital manufactures. In agriculture its promise is light too. For instance in mountain way the more precious vehicle control is needed for safe transportation. Its precision and rapidness to compare traditional vehicle is a main advantage [1,2]. Its corresponding to torque is directly and quickly as well. The rapidness is another important factor. It realizes the corresponding directly to driven shaft to tire with very high speed. It is easy to control. This will use widely on agriculture machinery. For instance agricultural mechanism eg. Tractor and other vehicles. Since traditional agricultural vehicles is heavy and slow they will wield precision control terrace in the future that is thought. For decreasing cost the electric vehicle will play a more role in agricultural machinery. From diesel to electrical resource the radical innovation is to come sooner. Because the diesel vehicle presents slow its efficiency is low although its power is strong. The construction and diesel price is high it is needed to change to more modern tool to fit to the agriculture functional machinery. For example the combined harvester and barley breaker is controlled item by cost, even use hybrid power vehicle recently. For the view of cost the decreasing it will be bright and available. For a long time it is a promise plan for us to further study. And then its non-contamination is secondly. Because the amount is not so much it is easy control so that it becomes still a disadvantage.

\section{DISCUSSION}

Agriculture machinery is a base as a first product power from old period. All the modern vehicle industry is derives from it as its second product power. So it is a significant topic to talk about its tool. Our modern important machine steamer is imitated from agricultural machinery ie. Yarn hinder machine. On Jan $29^{\text {th }}, 1886$ a famous Germany Karl Benz found the first Single cylinder gasoline vehicle engine for three tire vehicle that is first vehicle birthday. On Dec $31^{\text {st }}, 1879$ he found the first Single cylinder gas vehicle engine that was the first engine day before that birthday. $\mathrm{He}$ established Benz Corporation firstly in the world and lasted over one hundred years up to now. Now the world vehicle is from his find to make one after one miracle to help people to transport all the nearest affairs. Textile machinery is strong one to lead to modern machine including vehicle when it is in 19th century. It is a important machinery to make clothing to use for men to get warm and courtesy before this time. It can be used with our foot to drive and spin clothing before steamer occurred in 18th century which is found by Watt. It is said within reason that the yarn hinder machine ie original textile machinery is vehicle ancestor. 
Run Xu; Saudi J Eng Technol, Nov, 2020; 5(11): 413-415

In modern society the diesel vehicle takes a role in agriculture activity due to its strong power and toughness. It has contributed to much benefit to agriculture rice transplant, harvest and weeding. However the heavy and fool action affects its use for the future. The precious and rapid control is needed more and more. Some accidents happen in heavy control. If it is applied to precious work to guarantee high enough precision and tolerance. It must be a successful product-tool for function application. It may be easier and simpler than engine product. Only we need is an accumulator and motor. The hybrid vehicle (HV) is researched and developed by us now. This is a new technology vehicle that is constructed with two and above single driven systems rotating synchronously. In usual a hybrid vehicle presents the hybrid electric vehicle (HEV) that adopts a traditional engine and motor as power source. The engine uses diesel or gasoline and some engines use compressed natural gas, propane and ethyl alcohol as fuel. This is a method splitting the difference. On the road of complicating mountain the agricultural driver wants to control the vehicle slightly. If he drives heavily the accident will be easy to happen. It is needed to be softly and slowly to control a agricultural vehicle especially in heavy duty of cargo. For the life of driver the electric one is needed meantime the vehicle is expensive too. The electric vehicle is easy to control by a driver due to its precious and rapid response. Because there is not accelerating course gradually using foot pedal the power convey is direct and rapid, so if a driver has no mind to make accident it will be much safer than using traditional engine vehicle. So the electric agricultural vehicle is advocated big and prior. It can be advocated that test measurement is proceeded in priority. If we collect enough related data it can be evaluated and then judged correctly to agricultural one. Due to heavy duty it must be precious control the vehicle to avoid danger status in difficult road situation. For instance on a dangerous road status it must use precious and rapid response to drive and control, that is say, easy control. Only this way can a driver wield their subjective capability to complete his duty safe, preciously and rapidly. In a certain period precious delivery is much important for re-delivery and cost saving. These cargoes will occupy space and regulation so that they are in time arrival is also necessary. In time the distribution will be done. We can save many spirit and time. In long way to driving one the speed is key for delivering urge goods. So that it is urgent to transport them as possible. They must be handled quickly for their function utility. For instance a accident happen and many medical care device and drugs are needed due to many injured ones. We shall do delivery from near area to rescue and care them rapidly. Only if from hundred kilometers the vehicle carries many medical care goods to disaster spot rapidly as possible they can help many wounded ones cured and cared urgently. It is rapidness and precision problem. Many medical humans are to be carried this area to wield their curing roles. Agricultural vehicle can rapidly carry foods and clothes to them to be full of energy to precede their duty. In many fields the electric vehicle will wield its function more and more that is predicted in the near future. Not only the precision and rapidness is the electric vehicle owned but also the cost decreasing is it done. The cost decreasing is predominant more and more. The simple driven wheels can be completed by cost saving largely if the electric vehicle is adopted. The wheel motor can be manufactured with unified specification so that the many products is made by factories with low cost. The unified specification will promote the speed of motor producing as well and they can be produced in different factories and different area. They are made in every country and territories. The world can use unified specification to make components of motor simultaneously. For saving the energy and decreasing inflamed fuel discharge they are a necessary tool for agricultural development in future. As we know the diesel and gasoline is acquired through petrol exploiting and extract. But the electricity is done by wind, fire and water of nature resource. The utilized earth resource can be decreased largely by using electric vehicle. The engine structure is complicated but motor one is simple. The electricity charger is key. The battery is a role of transferring electricity energy into chemical energy through charger and release chemical one to mechanical rotation. The battery is a energy resource instead of engine in traditional vehicle. There is lead acid battery and lithium ion battery etc in current.

The complicated and sophisticated action is required in agriculture activity. The low cost is needed too in agriculture due to the complicated design and manufacture. That the design and manufacture decreases cost is our aim in electric vehicle. Only proposed the motor can we make the vehicle simply, which simplifies our design time and money as mush as possible. It can be made two or four wheel driven instead of the engine that saves our environment and decreasing inflame fuel with toxic Carbon and Nitrogen oxide. The low carbon and green life will be achieved by then. The resource waste will be decreased too for our generation to be conserved. We can breathe the fresh air naturally meantime the over resource exploiting is prohibited. We have green environment once again.

\section{CONCLUSIONS}

The electric vehicles are necessary in agriculture future due to their precision and rapidness. They are significant for their clear, safe \& non contamination to our live environment. Besides that the cost decreasing can make us to manufacture them with unified specification that allows us to produce rapidly and largely. 


\section{REFERENCES}

1. Chen, T.E. (2019). Chen Long etc, Estimation of Driving states based on pseudo-measurements of longitudinal force for distributed drive electric vehicles. Journal of Mechanical Engineering [J], 55(18):86

2. Zhang, L., Li, Liang, Qi, B. (2017). Decoupled roll stability control of in-wheel motor drive electric vehicle [J], 53(16): 94

\section{Brief Biography}

XU Run is a PHD completion one in school of Material Engineering Department in Geongsang National University. His research direction is material dynamics, metal process. Xurun1206@163.com 